\title{
EFEITO DE LISINA NO HÁBITO DE CRISTALIZAÇÃO DO CLORETO DE COBRE*
}

\author{
IBRAHIM OCTAVIO ABRAHÃo ** \\ Luiz Fernando Ribeiro DE Miranda ***
}

\section{RESUMO}

Estuda-se o hábito de cristalização do cloreto de cobre a partir da evaporação de soluções aquosas contendo lisina. São pesquisadas, com 3 repetições cada uma, 30 concentrações diferentes de lisina c cloreto de cobre, sendo 6 de lisina $(0,0005,0,0001,0,005$, $0,01,0,05$ e $0,1 \mathrm{~g}$ por placa) combinadas a 5 do sal $(0,125,0,25$, $0,5,0,75$ e $1,0 \mathrm{~g}$ por placa). Conclui-se que o modelo de cristalização é característico e pode ser reconhecido em extratos em que o efeito cristalogenético do aminoácido seja dominante. As melhores concentrações são as que combinam 0,25 a $0,50 \mathrm{~g}$ por placa de cloreto de cobre com 0,005 a $0,1 \mathrm{~g}$ por placa de lisina.

\section{INTRODUÇÃO}

O capítulo da cristalogênese do cloreto de cobre que pode ser considerado de maior precisão é o que trata da influência de substâncias químicas definidas, orgânicas ou inorgânicas, sobre o hábito de cristalização do sal. Isto se deve ao maior controle que se pode exercer sobre a influência específica do companheiro de solução do que quando se trabalha com extratos animais ou vegetais. A importância de se conhecer o efeito específico dessas substâncias decorre, principalmente, da possibilidade de serem detectadas pela cristalização sensitiva, quando presentes em extratos animais ou vegetais. É o caso de aminoácidos, pesquisados exaustivamente por SELAWRY e SELAWRY (1957): presentes em pequenas quantidades no sangue, o conhecimento de seus modelos permite avaliar seus efeitos no método de diagnose por cristalização. Nenhuma referência é feita por esse autor, todavia, ao modelo

\footnotetext{
* Enviado para publicação em 27/12/1976.

**ESALQ, USP.

*** Faculdade de Engenharia de Alimentos - UNICAMP.
} 
induzido por lisina, aminoácido que se reveste de particular importância agronômica pelo seu elevado teor em alguns tipos de milho e seu efeito na alimentação animal (ANDERSON, 1970).

O presente trabalho trata do estudo da influência desse aminoácido no hábito de cristalização do cloreto de cobre. A finalidade é estabelecer seu modelo de cristalização, com o que pode ser pesquisada sua presença em plantas.

\section{REVISÃO DA LITERATURA}

Embora já exista uma bibliografia relativamente extensa sobre a aplicação do método da cristalização sensitiva a questões referentes a animais e plantas, poucos trabalhos têm sido realizados com o objetivo de estabelecer os modelos de cristalização específicos de substâncias puras.

SELAWRY e SELAWRY (1957) tratam do assunto de maneira sistemática, descrevendo o efeito de substâncias inorgânicas, como sais ácidos e bases, e substâncias orgânicas, como alcoóis, aldeidos, vitaminas, hormônios, hidratos de carbono e aminoácidos. Mostram que os modelos de cristalização possuem características específicas para cada grupo e também individualmente, para cada substância. Estudam 14 aminoácidos: glicocol, alanina, asparagina, histidina, creatina, creatinina, metionina, cisteina, cistina, leucina, isoleucina, triptofano, tirosina e valina. Conclui que cada um comporta-se de maneira específica e sempre reprodutível e, para o grupo, separa os 7 primeiros dos 7 últimos como grupos de reação cristalogenética distinta. Não faz, todavia, nenhuma menção à lisina.

KLEBER e HARTUNG (1959) estudaram a cristalização do cloreto de cobre a partir de soluções aquosas com diferentes companheiros de solução. Pesquisaram 57 substâncias, entre sais de amônio, acetatos, cloretos, nitratos, sulfatos, ácidos, corantes, amido, albumina e outras substâncias orgânicas. Os cristais foram estudados por via química, ótica röntgenográfica. Concluíram que as adições podem ser separadas em 6 grupos, em função de sua influência sobre o cloreto de cobre: as indiferentes, as modificadoras de hábito (novas faces), as modificadoras de textura, as que dão origem a cristais mistos anômalos, como hóspedes na rede do cloreto de cobre, as que têm o cloreto de cobre como hóspede em sua rede, formando também soluções sólidas anômalas e as que formam ligações complexas com o cloreto. Sugeriram o possível efeito do $\mathrm{pH}$ no aparecimento de formas radiais, hipótese que não poderia, entretanto, ser generalizada. Com efeito, mesmo para as formas radiais, comuns em ácidos, os modelos de $\mathrm{HC} 1, \mathrm{HNO}_{3}$ e $\mathrm{H}_{2} \mathrm{SO}_{4}$ são totalmente diferentes (SELAWRY e SELAWRY, 1957). Os autores reconhecem a 
maior ação de processos complicados, que podem levar à formação de cristais mistos anômalos e complexos químicos.

Alguns trabalhos têm sido realizados com o objetivo de estabelecer a substância responsável pelo modelo de cristalização. MORRIS e MORRIS (1938), aplicaram a cristalização sensitiva a aveia, trigo, milho, amido e glicogênio. Obtiveram para cada tipo de cereal modelos sempre característicos, mas o amido obtido a partir de cada um produziu modelos sem diferenças aparentes. Constataram que a atividade dos extratos. diminui à temperatura ambiente, em 24 horas, mas permanece inalterada após aquecimento a $100^{\circ} \mathrm{C}$, por 10 minutos. Desenvolveram técnicas para concentração da fração ativa dos extratos. Obtiveram, como componente responsável pelo modelo, uma fração contendo $80 \%$ de polissacarídeo, calculado como $\mathrm{C}_{6} \mathrm{H}_{10} \mathrm{O}_{5}$.

Os mesmos autores trabalharam (1939) com glicogênio de origem animal e extratos de milho doce, isolando o polissacarídeo correspondente, aparentemente idêntico ao glicogênio. Seus modelos de cristalização, todavia, revelaram-se diferentes. Estudando esses glicogênios de diversas origens, concluíram que a cristalização sensitiva e o método das taxas de hidrólise enzimática fornecem critérios satisfatórios para sua diferenciação.

Ainda MORRIS e MORRIS (1941) observaram que pequenas quantidades de proteínas podem afetar sensivelmente os modelos produzidos por polissacarídeos e substâncias semelhantes, mas que a especificidade deve-se aos polissacarídeos.

\section{MATERIAL E MÉTODO}

\section{MATERIAL}

Foram usados lisina e cloreto de cobre p.a, Merck. Os demais materiais utilizados (câmara de cristalização, placas de vidro, material fotográfico, etc.) são os descritos por ABRAHÃO $(1965,1971)$.

\section{MÉTODO}

O processo geral de cristalização (preparo das soluções, nivelamento da mesa de vidro, limpeza das placas de cristalização, controle da umidade e da temperatura, decurso de cristalização) são os descritos por ABRAHÃO $(1965,1971)$.

Combinaram-se 6 concentrações de lisina $(0,0005,0,001,0,005,0,01$, 0,05 e $0,1 \mathrm{~g}$ por placa) com 5 concentrações de cloreto de cobre $(0,125$, $\mathbf{0}, 25,0,5,0,75$ e $1,0 \mathrm{~g}$ por placa). Obtiveram-se, então, 30 concentrações 
mútuas que foram cristalizadas com 3 repetições, levando-se à câmara 3 ou 4 séries de cada vez. Obtidos os modelos de cristalização, efetuou-se o julgamento da identidade, escolhendo-se a repetição mais representativa. Esta foi, então, descrita nos principais caracteres morfológicos do hábito de cristalização: cor, centragem, coordenação, irradiação, diferenciação geral, individualidade, espessamentos, anéis concêntricos, cobertura, formas vazias, espaços vazios, cristalização fibrosa, tipo de borda. As 30 placas representativas foram fotografadas para comparações posteriores.

\section{RESULTADOS E DISCUSSÃO}

De um modo geral, todas as séries podem ser descritas como de identidade boa a excelente, o que assegura a caracterização do modelo de lisina.

Algumas características morfológicas do modelo de cristalização de lisina podem ser estabelecidas. A cristalização é fina, com cristais de pequenos calibre e individualidade. O número de centros de cristalização é variável, predominando o modelo multicentrado (figs. 6 a 12), que chega a ser característico. A ramificação imediata a partir desses centros é dendrítica e abundante (figs. 7 e 8). Característicamente, o modelo não apresenta formas vazias ou mesmo tendência para sua formação. Também é característica a ausência de borda diferenciada. Em muitos casos, a borda está ausente, mas é muito típica a ocorrência de espaço circular sem cristais, ao redor de cristalização central (figs. 4, 6 e 10).

O modelo caracteriza-se, pois, por formas radiais, o que, associado à ausência de formas vazias, folhas ou rosetas, permite enquadrá-lo no tipo morfológico da leucina, descrito por SELAWRY e SELAWRY (1957).

Quanto às concentrações utilizadas, apresenta-se uma breve análise dos modelos, na ordem crescente das concentrações de lisina.

Concentração $0,0005 \mathrm{~g} /$ placa - A influência é não característica para 0,125 de cloreto, começando a se caracterizar a partir de 0,25. Para 1,0 de cloreto, a cobertura é total, com cristalização fibrosa. O modelo tende a se caracterizar para quantidades crescentes de cloreto de cobre, a partir de 0,25 (figs. 1, 2 e 3), embora a quantidade de lisina seja insuficiente.

Concentração 0,001 $\mathrm{g} /$ placa - Para 0,125 de cloreto de cobre a influência é não característica (fig. 4). O excesso de cloreto já ocorre, todavia, para as concentrações $0,5,0,75$ e 1,0, com cristalização fibrosa. Resulta, então, que o melhor modelo é para 0,25 de cloreto, que contém ainda caracteres de insuficiência de lisina. 
Concentração $0,05 \mathrm{~g} /$ placa - Para 0,125 a influência é não característica, mas o modelo já mostra alguns caracteres típicos, como número de centros. A melhor concentração para cloreto é 0,25 , com centragem característica (fig. 5), enquanto 0,75 e 1,0 são excessivas.

Concentração $0,01 \mathrm{~g} /$ placa - O modelo já exibe diferenciação característica para 0,125 de cloreto, embora o modelo restrinja-se a pequena cristalização central multicentrada. A melhor concentração é 0,25 (fig. 7). O excesso de cloreto já se revela para 0,05 , com início de cristalização fibrosa (fig. 8), tornando-se a cobertura total para 0,75 e 1,0.

Concentração 0,05 g/placa - O melhor modelo ocorre novamente para 0,25 de cloreto de cobre (fig. 9), sendo equivalente ao das concentrações anteriores de lisina. A partir de 0,5 a concentração de cloreto é excessiva, provocando cobertura total.

Concentração $0,1 \mathrm{~g} /$ placa - Não ocorre nenhum modelo de influência não característica, assim como é a única concentração em que cobertura total não ocorre, para 0,75 e 1,0. O modelo já se define com a concentração 0,125 de cloreto. Apartir de 0,25, observa-se um modelo altamente característico (figs. 10, 11 e 12), que persiste mesmo na concentração 1,0 de cloreto de cobre. Trata-se de um modelo multicentrado, característico e facilmente reconhecido.

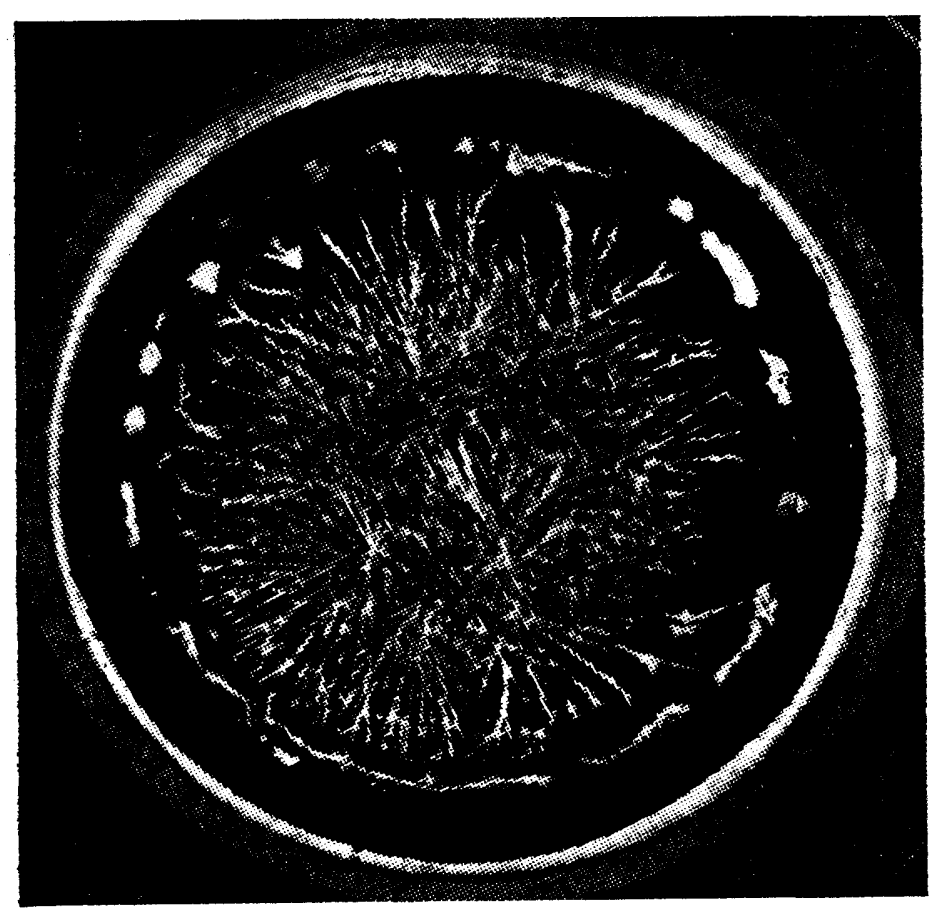

Fig. $1-0,0005: 0,25\left(x^{2} / 3\right)$

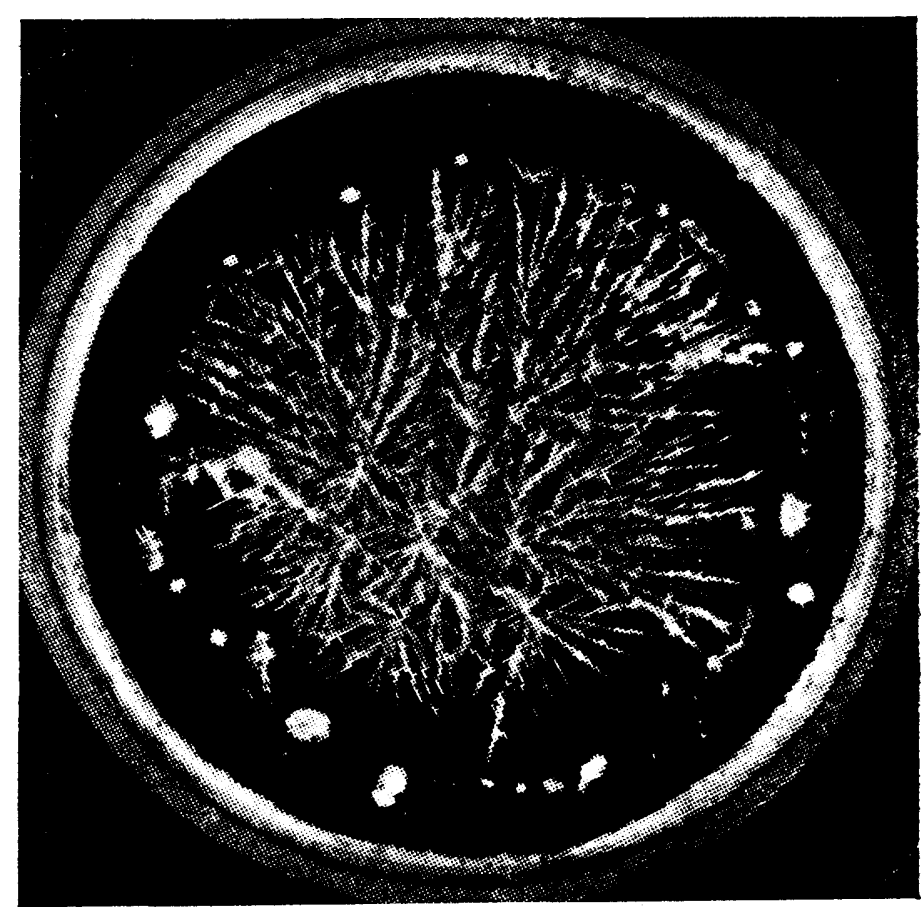

Fig. $2-0,0005: 0,5\left(x^{2} / 3\right)$ 


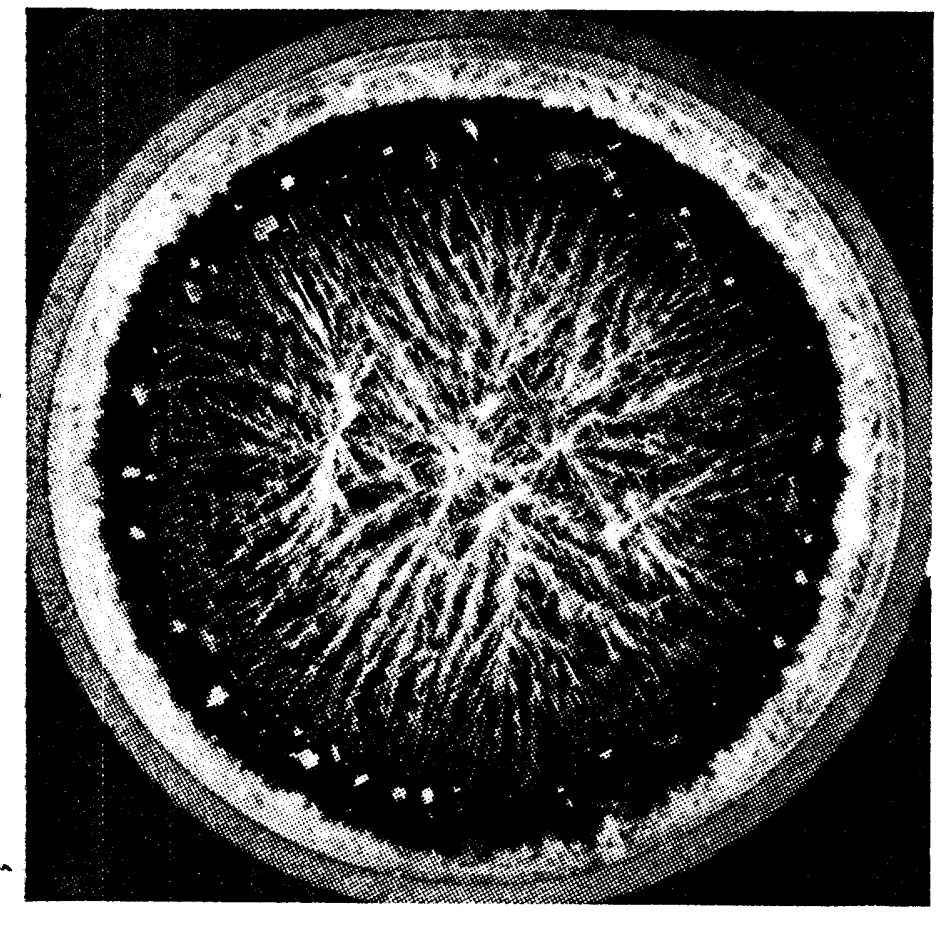

Fig. $3-0,00075: 0,75\left(x^{2} / 3\right)$

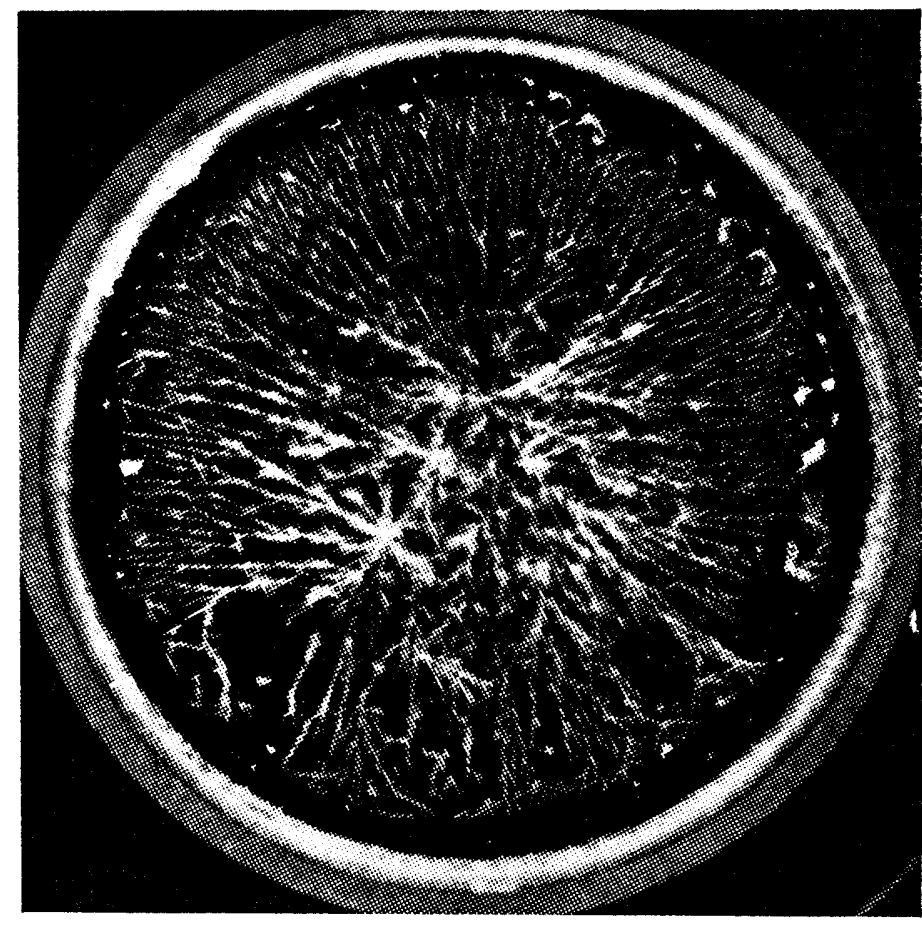

Fig. $4-0,001: 0,25(\mathrm{x} 2,3)$

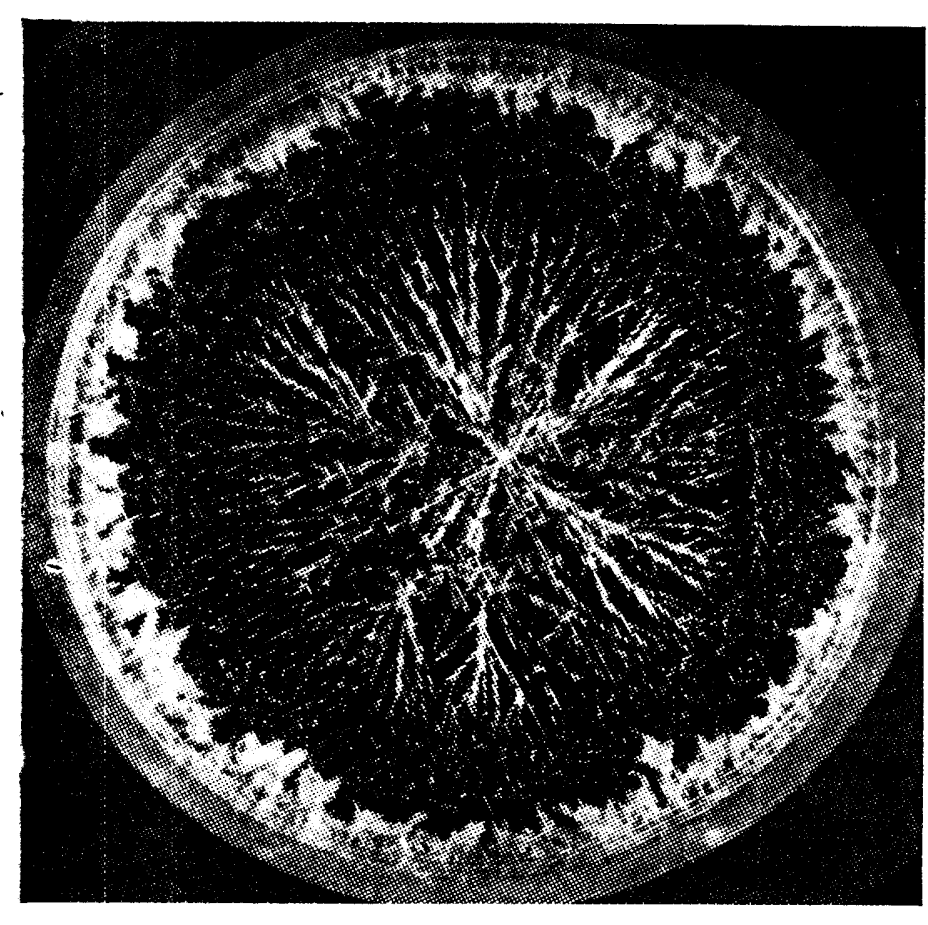

Fig. $5-0,005: 0,25(x 23)$

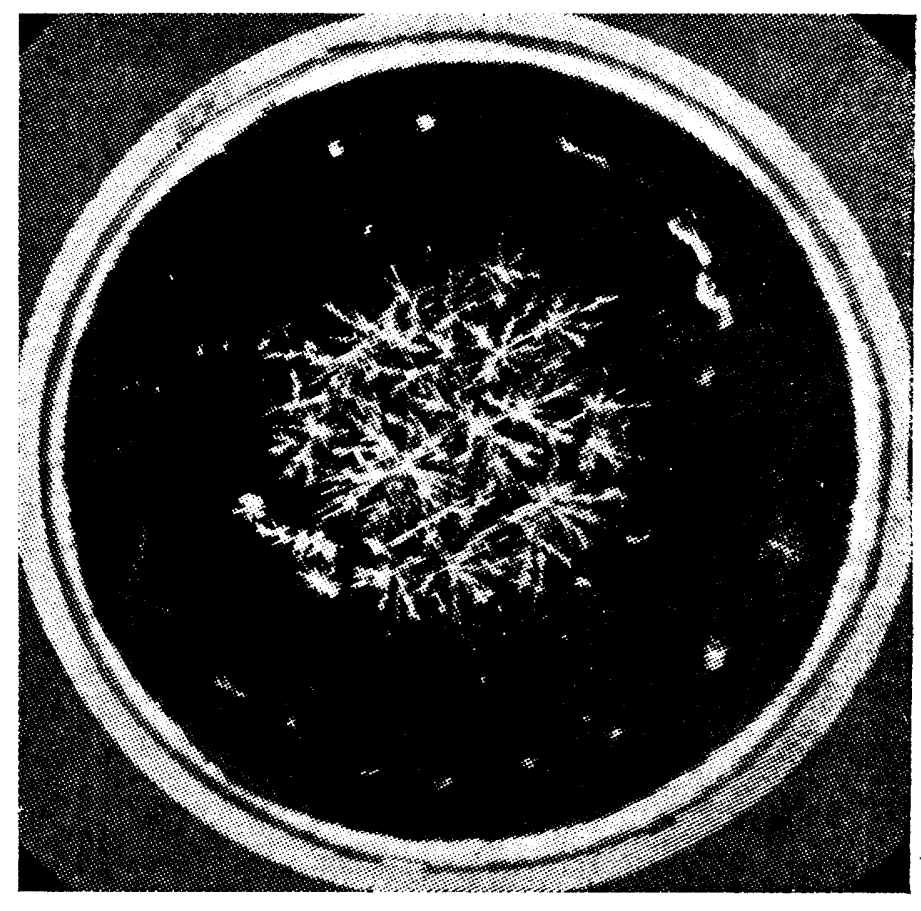

Fig. $6-0,01: 0,125\left(x^{2 / 3}\right)$ 


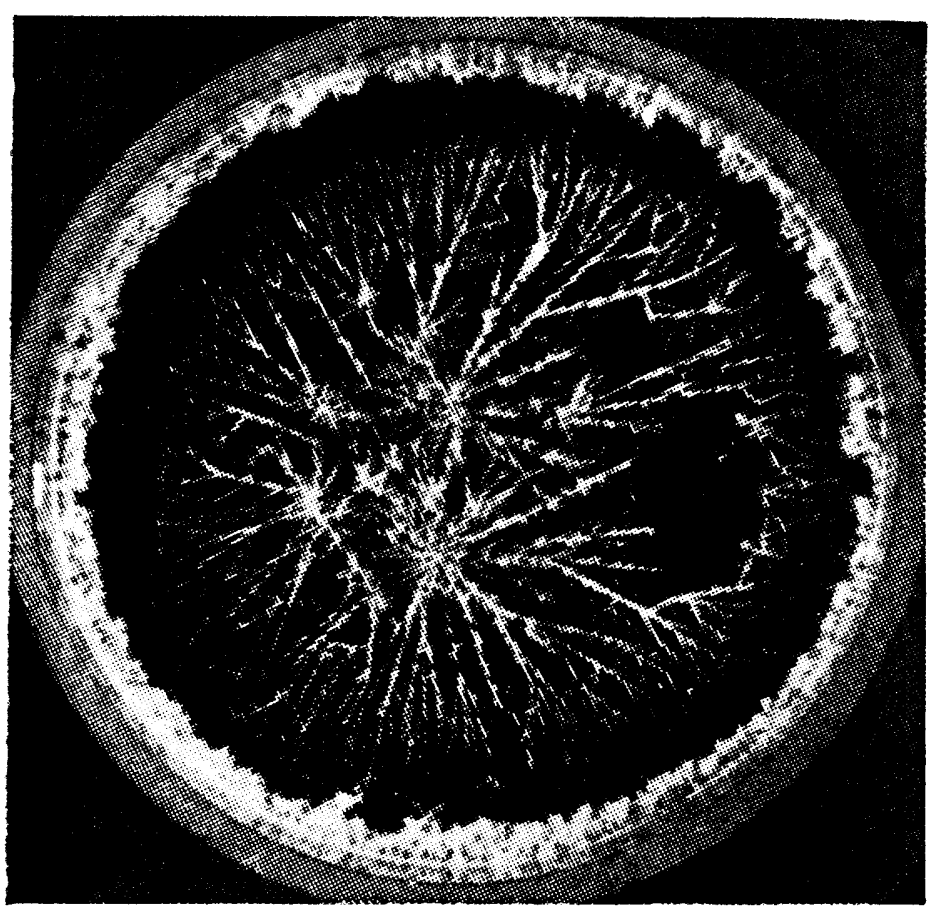

Fig. $7-0,01: 0,25\left(x^{2} / 3\right)$

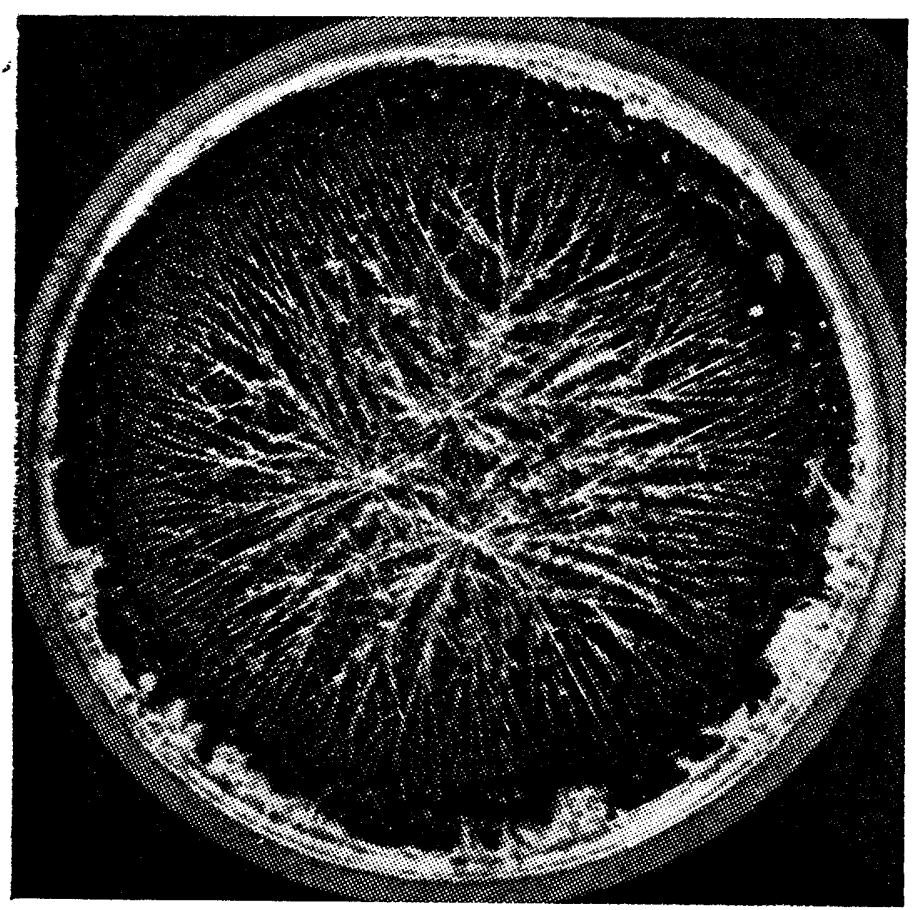

Fig. $9-0,05: 0,25\left(x^{2} / 3\right)$

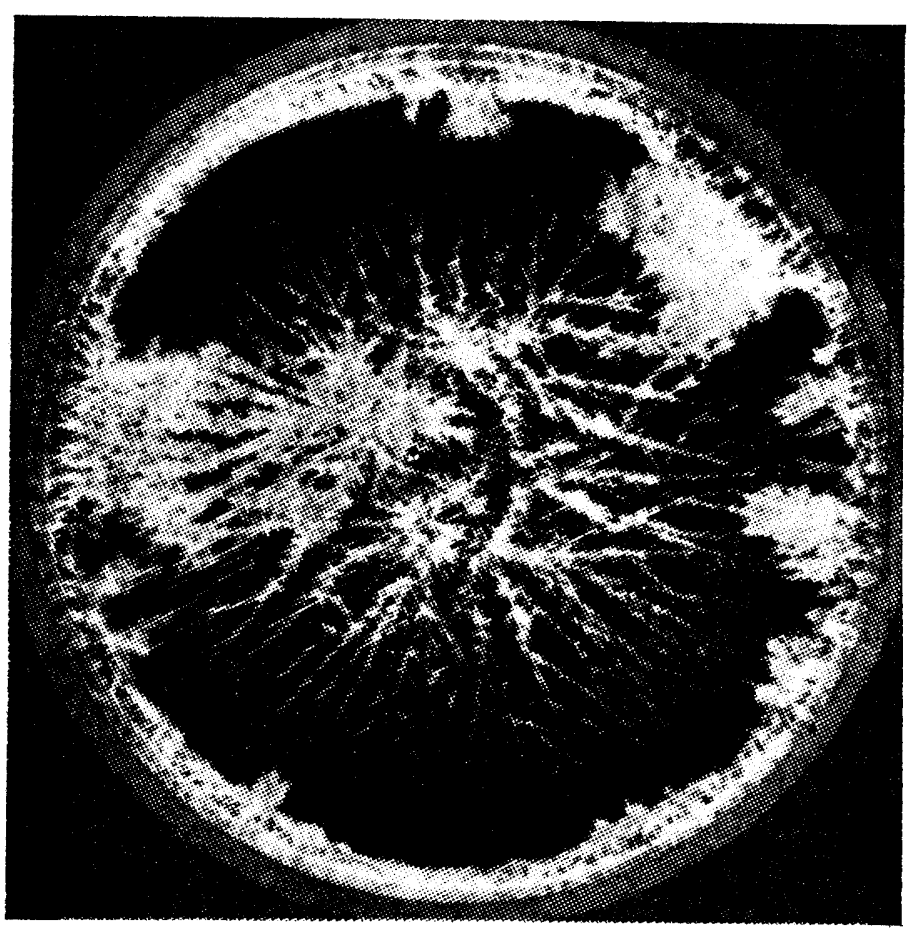

Fig. $8-0,01: 0,5\left(x^{2} / 3\right)$

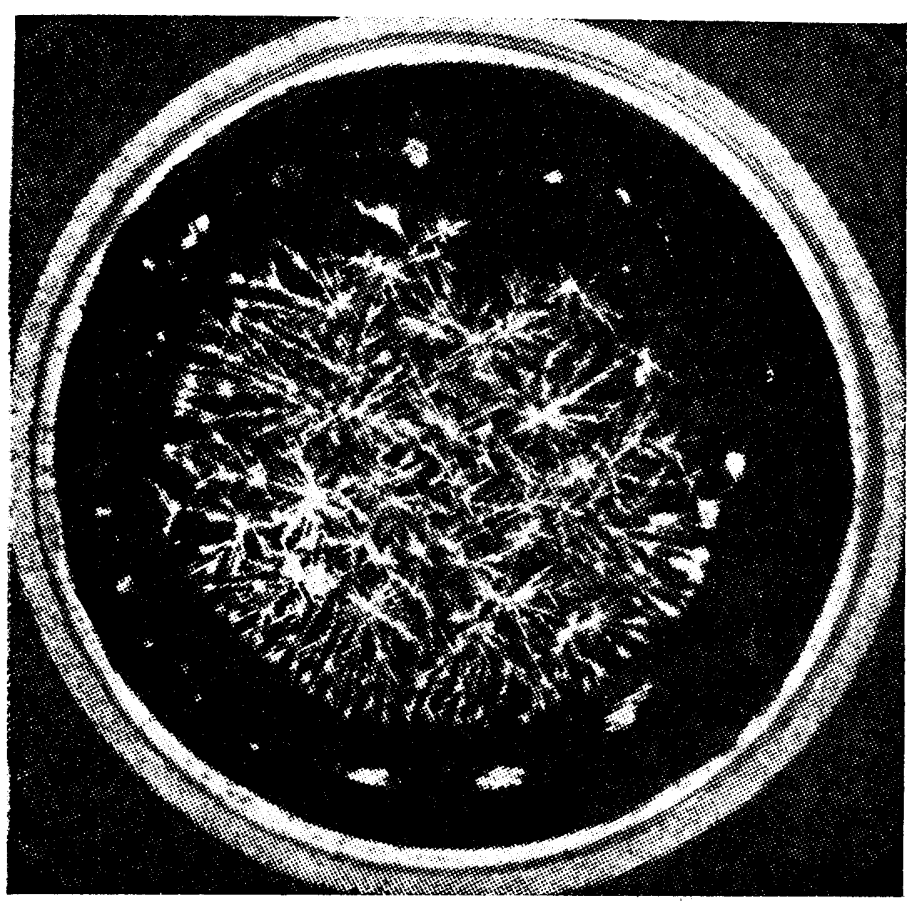

Fig. $10-0,1: 0,25\left(x_{2 / 3}\right)$ 


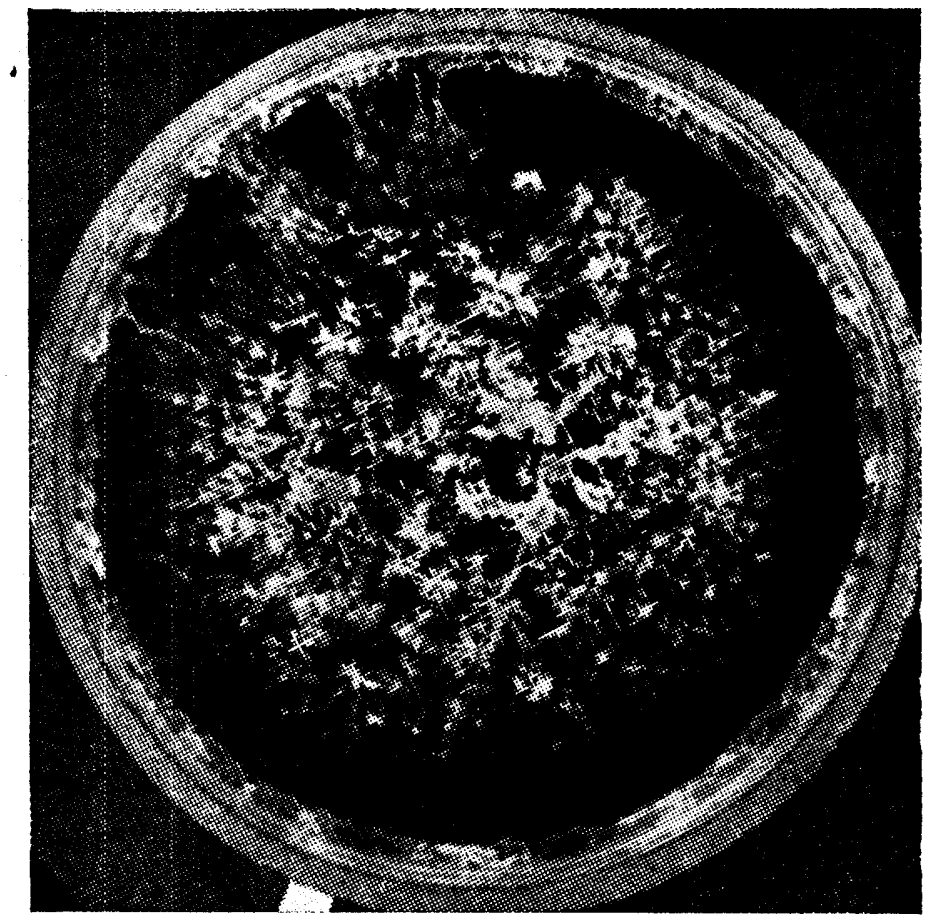

Fig. $11-0,1: 0,25\left(x^{2} / 3\right)$

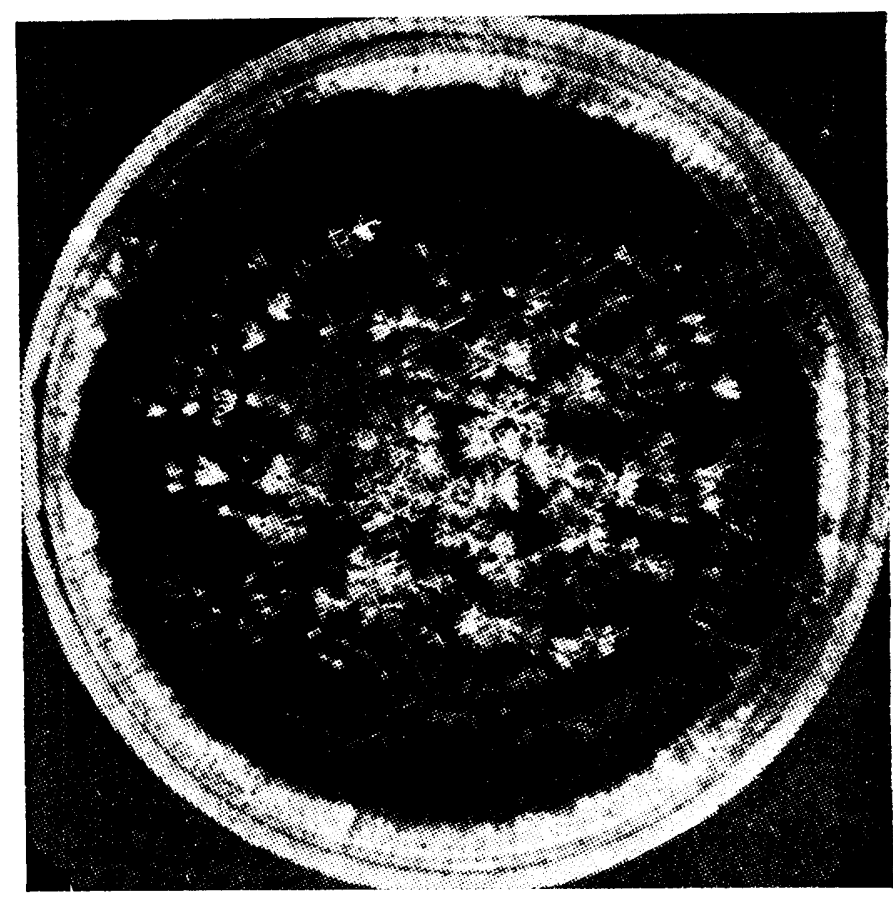

Fig. $12-0,1: 0,75\left(\mathrm{x}^{2} / 3\right)$

\section{CONCLUSÕES}

O modelo de lisina é característico e, nas concentrações adequadas, é reconhecido com facilidade. Pode ser enquadrado no grupo morfológico de leucina, pela sua centragem e pela freqüência de formas radiais.

A concentração $0,0005 \mathrm{~g} /$ placa de lisina é insuficiente para modelar a cristalização. As concentrações de cloreto de 0,75 e 1,0 g/placa podem ser consideradas excessivas, mascarando o modelo do aminoácido, exceto para $0,1 \mathrm{~g} /$ placa deste.

A melhor concentração para cloreto de cobre é $0,25 \mathrm{~g} /$ placa, que produz modelos característicos com a maior parte das concentrações de lisina. As melhores concentrações de lisina são 0,01, 0,05 e 0,1 g/placa, esta última exigindo maiores concentrações de cloreto de cobre.

Em face do caráter típico do modelo de cristalização de lisina, sugere-se que o método seja aplicado a variedades de milho contendo proporções variáveis de lisina. 


\section{SUMMARY}

\section{EFFECT OF LYSIN ON THE CRYSTALLIZATION HABIT OF COPPER CHLORIDE}

This paper deals with the crystallization habit of copper chloride obtained from the evaporation of an aqueous solution containing lysin. The 30 concentrations studied were the result of combining 6 concentration of lysin $(0,005,0,001,0,005,0,01,0,05$ and 0,1 $\mathrm{g} /$ plate) to 5 concentrations of copper chloride $(0,125,0,25,0,5,0,75$ and $1,0 \mathrm{~g} / \mathrm{plate})$. The main conclusion is that the crystallization pattern is characteristic and can be recognized in crystals obtained from extracts in whicb the crystallogenetic effect of the aminoacid is dominant. The best concentrations were those combining 0,25 to $0,5 \mathrm{~g} /$ plate of copper chloride with 0,005 to $0,1 \mathrm{~g} /$ plate of lysin.

\section{LITERATURA CITADA}

ABRAHÃO, I.O., 1965 - Cristalogênese do cloreto de cobre. Aplicação do método de Pfeiffer ao feijoeiro (Phaseolus vulgaris L.). Tese de doutoramento, ESALQ - USP, Piracicaba, 134 pp.

ABRAHÃO, I.O., 1971 - Morfologia do cloreto de cobre na presença de extratos aquosos de feijoeiro (Phaseolus vulgaris L.). Anais da ESALQ, vol. 28:199-216.

ANDERSON, J.C., 1970 - Milho de alto teor de lisina. Departamento e Instituto de Genética, ESALQ-USP, mimeografado, 6 pp.

KLEBER, W. e HARTUNG, U.S., 1959 - Ein Beitrag zur Kristallisation von Kupfer (II) - Chlorid - Dihydrat aus Lösungen. Zeitschrift für Kristallographie, Band III, Frankfurt, 213-234.

MORRIS, D.L. e MORRIS, C.T., 1938 - Specific effects of certain tissue extracts on the crystallization pattern of cupric chloride. Journal of Physical Chemistry, 43, 623-629.

MORRIS, D.L. e MORRIS, C.T., 1939 - Glycogen in the seed of Zea mays (variety golden bantam). The Journal of Biological Chemistry, Baltimore, vol. 130, 535-544.

MORRIS, D.L. e MORRIS, C.T., 1940 - The modification of cupric chloride crystallization patterns by traces of proteins. The Journal of Biological Chemistry, Baltimore, vol. 141, 515-521.

SELAWRY, A. e SELAWRY, O., 1957 - Die Kupferchlorid kristallisation in Naturwissenschaft und Medicin. Gustav Fischer - Verlag, Stuttgart, 232 pp. 
